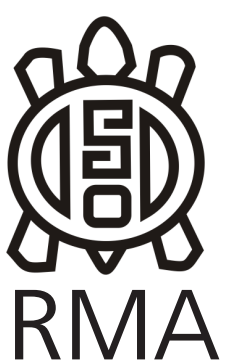

Arqueología

\title{
Caracterización tecnomorfológica de dos conjuntos líticos del Holoceno medio en la Estepa Fueguina: La Arcillosa 2 y Río Chico 1
}

\author{
Mónica Salemme*, **, Jimena Oría*, \\ Lucas Turnes* y Fernando Santiago*
}

\begin{abstract}
*Laboratorio de Geomorfología y Cuaternario, Centro Austral de Investigaciones Científicas - CONICET, B. Houssay 200, Ushuaia. E-mail: msalemme@cadic-conicet. gob.ar, jimenaoria@hotmail.com, Iturnes@hotmail.com, ersant2@gmail.com

** Universidad Nacional de Tierra del Fuego, Onas 450, Ushuaia
\end{abstract}

\begin{abstract}
Resumen
Con el objetivo de ampliar el conocimiento de la tecnología lítica asignable al Holoceno medio, en este artículo se presenta un análisis comparativo de dos conjuntos recuperados en posición estratigráfica, ambos depositados en un paleoacantilado de la costa atlántica de Tierra del Fuego: La Arcillosa 2, fechado entre $3690 \pm 70$ y $4440 \pm$ 60 ARCP, y Río Chico 1, datado entre $4476 \pm 43$ y $5828 \pm 46$ ARCP. Son concheros de limitada extensión y escasa concentración, que representan ocupaciones breves y contienen material lítico y faunístico; por debajo del conchero de La Arcillosa 2 se verificó un evento de inhumación. La información aquí presentada contempla aspectos tecnomorfológicos, buscando con ello caracterizar los distintos contextos en el marco de las evidencias conocidas a nivel regional para este período. Los resultados apuntan a obtener una caracterización general de los conjuntos líticos asignables a dicha cronología.
\end{abstract}

Palabras clave: cazadores-recolectores; concheros; tecnología lítica; Holoceno medio; estepa fueguina

Technomorphological characterization of two lithic assemblages of the middle Holocene in the Fuegian Steppe: La Arcillosa 2 and Río Chico 1

\begin{abstract}
This contribution presents a comparative analysis between two lithic assemblages coming from stratigraphy, with the main goal of improving the knowledge of the lithic artifacts assigned to middle Holocene. Both assemblages come from small shellmiddens deposited in a paleocliff of the Atlantic coast; they are scarcely concentrated and represent short occupations where faunal (vertebrates and invertebrates) and lithic materials are associated. In one of these sites (LA2), a human skeleton was buried below the shell midden. Data herein presented describes technomorphological aspects. This study looks for the characterization of different lithic assemblages at a regional level in the framework of the known evidence for the middle Holocene.
\end{abstract}

Key words: hunter-gatherers; shellmiddens; lithic technology; middle Holocene; Fuegian steppe

La ocupación humana temprana en el sector norte de Tierra del Fuego está evidenciada en el sitio Tres Arroyos 1 (transición Pleistoceno-Holoceno) y en algunos registros del Holoceno medio (La Arcillosa, Río Chico 1, Cerro Bandurrias, Marazzi 2, Myren 2 y Monmouth 20). En cambio, para el Holoceno tardío los registros son mucho más variados y numerosos.

Los registros arqueológicos que datan desde ca. 2000 ARCP hasta principios del S XX, han sido asignados a grupos identificados como Selk'nam históricos y sus antecesores directos. A partir del análisis de las fuentes etnográficas y las contribuciones arqueológicas, los conjuntos líticos del Holoceno tardío se han caracterizado en base a una serie de rasgos recurrentes, registrándose puntas pedunculadas, raspadores frontales pequeños y raederas laterales. Tardíamente comienzan a utilizarse puntas pedunculadas pequeñas, relacionadas con la adopción del complejo arco y flecha.

A efectos de ampliar el conocimiento de las características tecnomorfológicas de artefactos líticos asignables al Holoceno medio, período temporal para el cual la información arqueológica aún es escasa, se presenta un

Recibido 09-04-2013. Recibido con correcciones 10-07-2013. Aceptado 10-12-2013 
análisis comparativo de dos conjuntos. Ambos proceden de concheros de acotada extensión, que representan ocupaciones efímeras. Estos sitios están ubicados en un paleoacantilado de la costa atlántica de Tierra del Fuego: La Arcillosa 2 (LA2) y Río Chico 1 (RCh1) que contienen material lítico asociado a restos faunísticos y malacológicos (Salemme et al. 2007a; Santiago et al. 2007).

Los sitios se ubican en la estepa fueguina, un ambiente donde prevalece un clima templado-frío con influencia oceánica (Coronato 2007). La temperatura media anual es de $5,5^{\circ} \mathrm{C}$, siendo las temperaturas promedio mensuales más altas de $10,5^{\circ} \mathrm{C}$ en enero y las más bajas de $0^{\circ}$ en julio (Iturraspe y Urciuolo 2007). Las precipitaciones oscilan entre 300 y 350 mm, lo cual caracteriza el paisaje de mayor aridez para esta región insular (Cogliati y Cuello 2007; Coronato 2007). Los constantes vientos del oestesudoeste producen un efecto de desecación en verano y de enfriamiento en invierno. El viento, además, como uno de los principales agentes que contribuyen a la degradación del suelo, restringe la diversidad de la flora, especialmente en las planicies esteparias. La vegetación herbácea se caracteriza por diversos tipos de coironales y arbustos que crecen en matorrales (Collado 2007), cubriendo prácticamente toda la superficie. La acción del viento y esta cobertura vegetal actúan facilitando y/o dificultando, respectivamente, la visibilidad arqueológica (Oría 2012).

En este paisaje, el registro arqueológico se hace particularmente visible en áreas denudadas por el pisoteo animal y la acción eólica posterior, por ejemplo en hoyadas de deflación, en laderas degradadas por sobrepastoreo o bien en sectores costeros.

\section{Antecedentes}

\section{El Holoceno medio en Tierra del Fuego}

Los contextos arqueológicos asignados al Holoceno medio en la estepa de Tierra del Fuego se distribuyen en un amplio sector del norte de la isla (Figura 1), generalmente vinculados a zonas costeras. Sólo en un único sitio, Tres Arroyos 1, se han registrado ocupaciones más antiguas, así como otras que pertenecen al Holoceno tardío, pero allí no se hallaron ocupaciones del período que interesa en este artículo. Este sitio representa la ocupación más temprana del sector, ocurrida previamente a la inundación del Estrecho de Magallanes por el mar (McCulloch et al. 2005; McCulloch y Morello 2009; Rabassa et al. 2009).

En el sector chileno han sido excavados tres contextos en estratigrafía: Marazzi 1, Monmouth 20 y Myren 2 (Figura 1), a los cuales se suman dos contextos sondeados y datados para finales del Holoceno medio: Porvenir Norte 12 y Marazzi 13 (Morello et al. 2009a, 2012). Las respectivas edades radiocarbónicas se presentan en la Tabla 1.

Laming-Emperaire y colaboradores describen la localidad Marazzi como "una serie de sitios que incluía concheros parcial o totalmente erosionados, campamentos ubicados en el loess o en la arena de las terrazas (también erosionadas en mayor o menor grado) y un alero bajo roca" (Laming Emperaire et al. 1972: 225). Este último sitio al que hacen referencia es Marazzi 1, emplazado en un alero formado en la cara norte de un

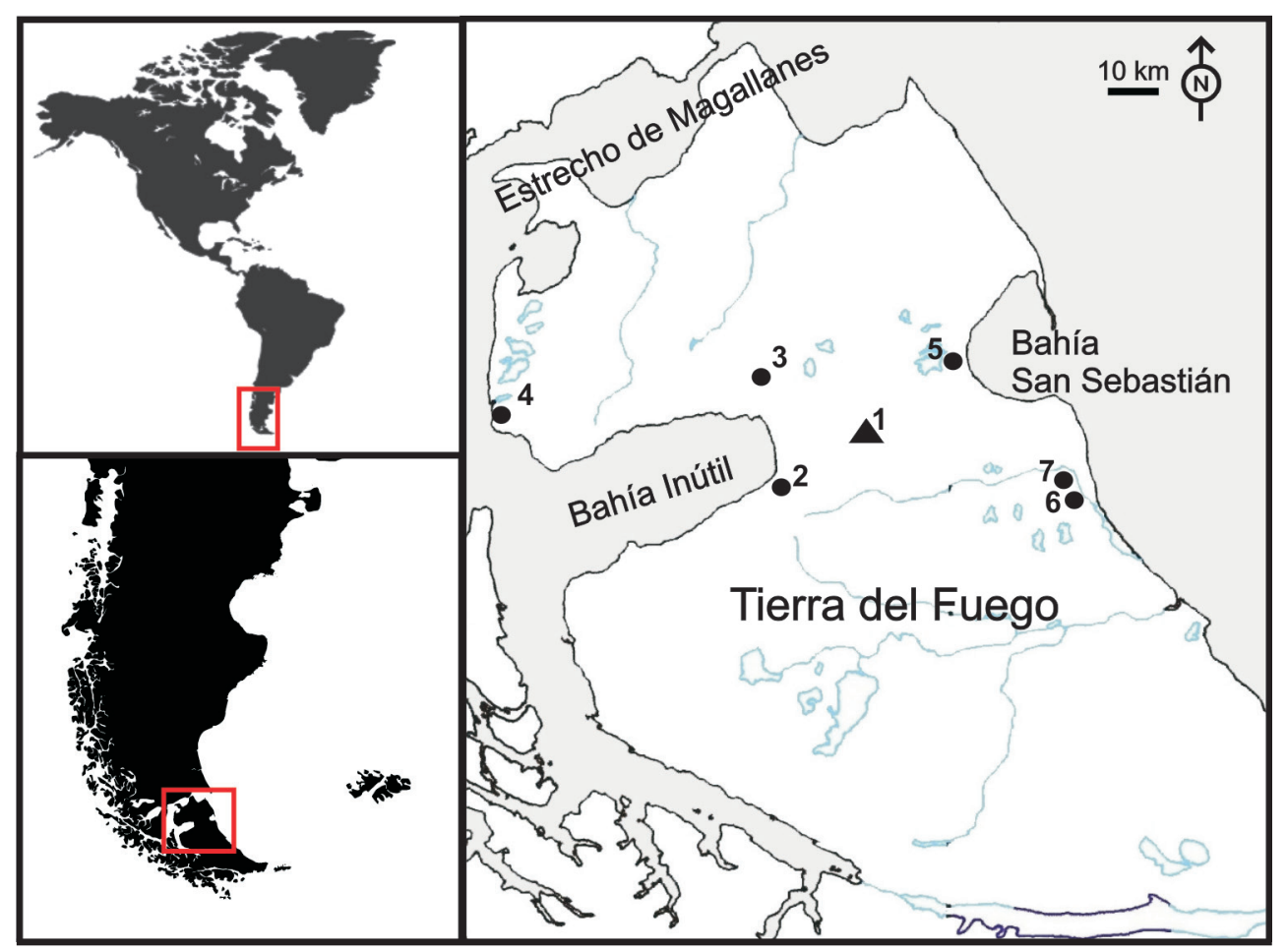

Figura 1. Distribución de los sitios del Pleistoceno final (triángulo) y Holoceno medio (círculos) en el norte de la Isla Grande de Tierra del Fuego. 1: Tres Arroyos 1; 2: Marazzi 1; 3: Myren 2; 4: Monmouth 20; 5 : Cerro Bandurrias; 6: localidad La Arcillosa; 7: Río Chico 1.

Figure 1. Distribution of late Pleistocene (triangle) and middle Holocene sites (circles) in the north of the island of Tierra del Fuego. 1: Tres Arroyos 1; 2: Marazzi 1; 3: Myren 2; 4: Monmouth 20; 5: Cerro Bandurrias; 6: La Arcillosa Locality; 7: Río Chico 1. 
bloque errático. En 1965 se descubrieron dos sepulturas y varios niveles arqueológicos. Se dató carbón proveniente del fondo del sondeo, que arrojó una edad de $9590 \pm$ 200 años ARCP. Este último fechado ha sido discutido por Morello y colaboradores (Morello et al. 1999, 2012), cuyas investigaciones advierten acerca de la complejidad presente en los procesos de formación del sitio. Nuevos fechados registran una antigüedad máxima de $8840 \pm$ 50 ARCP en un suelo enterrado, aunque también en esta misma unidad se dató material óseo en $4550 \pm$ 30 ARCP (Morello et al. 2012). En síntesis, el fechado más temprano aceptado para este sitio corresponde al Holoceno medio (5440 \pm 30 ARCP, Tabla 1).

Durante la década del 90' se publicaron diversos trabajos que incrementaron la información sobre esta localidad. Se analizaron los restos óseos humanos provenientes de Marazzi 1, asignados al nivel arqueológico del Holoceno medio, que evidenciaron la práctica de cremación como tratamiento mortuorio (Guichón 1994). El sitio volvió a excavarse, logrando una nueva interpretación estratigráfica del mismo como así también un nuevo fechado (Morello et al. 1999) y la colección Marazzi 1 fue reestudiada (Morello 2000).

El sitio Monmouth 20 está emplazado en una terraza paleolacustre del Último Máximo Glacial. Tiene una densidad baja de materiales óseos, pero los artefactos líticos están bien representados e incluyen diversas actividades de talla, entre las que se cuentan las primeras etapas de desbaste de núcleos (Morello et al. 2009b).

El sitio Myren 2 se ubica 14 km al interior de bahía Inútil y posee tres fechados (Tabla 1) que datan el conjunto en el lapso Holoceno medio-tardío. En él abundan los huesos de guanaco y, en menor medida, artefactos líticos como raederas denticuladas y bolas, los cuales fueron manufacturados sobre una amplia variedad de materias primas. El componente lítico evidencia el uso de estrategias tecnológicas tanto conservadas como expeditivas (Prieto et al. 2007).

Para este mismo intervalo, aunque con menor cantidad de información contextual, únicamente procedente de sondeos, se encuentran los sitios Porvenir Norte 12, ubicado en una terraza de aproximadamente 5 a $6 \mathrm{msnm}$, sobre depósitos de la transgresión marina del Holoceno medio, al norte de la ciudad de Porvenir, y Marazzi 13, Bloque de la Obsidiana, situado unos kilómetros al este de la costa de bahía Inútil (Morello et al. 2009a). El sitio Porvenir Norte 12 constituye una amplia dispersión de material, identificándose en estratigrafía gran cantidad de ítems líticos, arqueofaunísticos y malacológicos. Los artefactos líticos recuperados incluyen un núcleo, lascas y desechos de bola. Por otra parte, el registro arqueofaunístico está conformado por restos de guanaco,

\begin{tabular}{llll}
\hline \multicolumn{1}{c}{ Sitio y unidad } & Años ARCP & Material & Referencia \\
\hline Marazzi 1 & $5570 \pm 400$ & carbón & Laming Emperaire et al. 1972 \\
Marazzi 1 & $5440 \pm 30$ & guanaco & Morello et al. 1999 \\
Marazzi 1 & $6170 \pm 50$ & Mytilus sp. & Morello at al. 2012 \\
Monmouth 20 & $5520 \pm 50$ & valva & Morello et al. 2009b \\
Myren 2 & $3820 \pm 35$ & guanaco & Prieto et al. 2007 \\
Myren 2 & $3910 \pm 70$ & guanaco & Prieto et al. 2007 \\
Myren 2 & $4020 \pm 35$ & guanaco & Prieto et al. 2007 \\
Porvenir Norte 12 & $3850 \pm 70$ & Mytilus sp & Morello et al. 2009a \\
Marazzi 13 & $3930 \pm 40$ & carbón & Morello et al. 2009a \\
Co Bandurrias & $5700 \pm 180$ & valva & Favier Dubois y Borrero 2005 \\
La Arcillosa 1 & $5410 \pm 70$ & Mytilus sp & Salemme y Bujalesky 2000 \\
La Arcillosa 3 & $5353 \pm 53$ & Mytilus sp & Salemme y Bujalesky 2000 \\
La Arcillosa 2 & $4440 \pm 60$ & Mytilus sp. & Salemme y Bujalesky 2000 \\
La Arcillosa 2 & $3690 \pm 70$ & Mytilus sp, & Salemme y Bujalesky 2000 \\
La Arcillosa 2 & $5508 \pm 48$ & Mytilus sp. & Salemme et al. 2007 a,b \\
La Arcillosa 2 & $5205 \pm 58$ & H. sapiens & Salemme et al. 2007 a,b \\
Río Chico 1 & $4476 \pm 43$ & carbón & Santiago et al. 2007 \\
Río Chico 1 & $5828 \pm 46$ & hueso quemado & Santiago et al. 2007 \\
Río Chico 1 & $5856 \pm 44$ & Mytilus sp. & Santiago et al. 2007 \\
\hline
\end{tabular}

Tabla 1. Fechados radiocarbónicos conocidos para los contextos del Holoceno medio.

Table 1. Radiocarbon datings of middle Holocene contexts. 
aves, roedores y cetáceo (Morello et al. 2009a).

El sitio Marazzi 13 se caracteriza por el hallazgo de lascas de obsidiana negra y verde en superficie y estratigrafía, además de otras materias primas en baja cantidad, asociadas a fragmentos de carbón y a una lente carbonosa, del cual se dató una muestra (Morello et al. 2009a, 2012).

En el sector argentino del norte de la isla, los contextos del Holoceno medio son cinco: Cerro Bandurrias, La Arcillosa 1, 2 y 3 y Río Chico 1 (ver Tabla 1 y Figura 1).

En el Cerro Bandurrias, ubicado a 3,5 km de la línea de costa actual, la presencia de algunos sectores deflacionados favoreció la exposición de material arqueológico en superficie. En la ladera oriental, sobre la base de la cubierta eólica, se registró una lente de Mytilus sp. que aflora a lo largo de $2 \mathrm{~m}$ y tiene un espesor de $15 \mathrm{~cm}$ y fue fechada en $5700 \pm 180$ ARCP (Favier Dubois y Borrero 2005). La lente de valvas fue excavada pero no se registraron materiales culturales. Sin embargo, estos autores proponen que es de origen antrópico en base a la interpretación de una serie de rasgos, como la presencia exclusiva de Mytilus, especie que no se encuentra en los depósitos que rodean al cerro y que se considera transportada. Según los autores, "la geometría del depósito, su localización y la presencia de una única especie sugieren un origen cultural para esta lente de valvas" (Favier Dubois y Borrero 2005: 102).

\section{Los contextos analizados}

La localidad La Arcillosa (Figura 1) está compuesta por 3 sitios (LA 1, 2 y 3). Los tres se encuentran en un sedimento eólico depositado sobre un afloramiento Terciario, en la barranca de la margen derecha del río Chico, en la base del cerro La Arcillosa (Salemme et al. 2007a). LA1 se describe como una línea de valvas escasas, huesos de guanaco fragmentados y muy pocas lascas en superficie (Salemme y Bujalesky 2000). Por su parte, LA3 está representado por una lente de valvas con escaso material lítico y fragmentos óseos.

LA2 se ubica unos 1000 metros al noroeste de los sitios antes mencionados, en la parte alta de la barranca (paleoacantilado), en una hoyada de deflación abierta en sedimento eólico arenoso, quedando expuesta una capa de conchero en estratigrafía de una longitud de aproximadamente 10 metros. Mediante sondeos se constató la continuidad del nivel de conchero en una superficie de al menos $100 \mathrm{~m}^{2}$ (Salemme y Bujalesky 2000), con una potencia variable entre 10 y $30 \mathrm{~cm}$ aproximadamente. En esta capa se recuperaron huesos de peces, aves y mamíferos tanto terrestres como marinos, valvas enteras y fracturadas y artefactos líticos. También se registró material arqueológico en superficie (Salemme y Bujalesky 2000; Salemme et al. 2007a, 2014).
En este sitio se realizaron tres excavaciones que alcanzan los $10 \mathrm{~m}^{2}$ y dos recolecciones de superficie, en un reticulado de cinco cuadrículas en el sector más cercano a la excavación (sector 1) y siete cuadrículas en otro sector algo más alejado de la concentración principal, hacia el noreste (sector 2) (Salemme et al. 2007a; Santiago 2013). Estas recolecciones se realizaron en un sector colindante a la cuadrícula excavada. Esto implica que son materiales que no se hallaron en asociación primaria; sin embargo, dada su proximidad se consideró que guardan relación con los materiales provenientes de la excavación debido a las semejanzas que presentan en el tipo de materias primas, las proporciones entre desechos y artefactos formatizados y algunas relaciones de ensamblaje logradas entre piezas de estratigrafía y de superficie (Salemme et al. 2007a, Santiago 2013). Durante las primeras dos excavaciones y la recolección superficial del sector 1 se recuperaron 408 artefactos líticos (Santiago 2013) mientras que en la última excavación se hallaron otros 523 materiales líticos, sumando un total de 931 ítems (Tabla 2). Por otra parte, el total de restos faunísticos recuperados durante las diferentes instancias de trabajo de campo asciende a 986 especímenes (Salemme et al. 2014).

En la cuadrícula 1, por debajo de la capa de conchero, se recuperó un esqueleto humano completo y articulado en posición genuflexionada, sobre el lateral derecho (Salemme et al. 2007 a y b, Santiago et al. 2011). Algunas valvas de Mytilus enteras y en posición horizontal (sin evidencias de desplazamiento vertical) encontradas en contacto con el esqueleto, fueron datadas (Tabla 1) (Salemme et al. 2007 a y b).

Mediante una prospección geofísica (GPR) se realizó un sondeo del sitio en diversos puntos, en parte sobre la base de las cuadrículas originalmente excavadas, totalizando una superficie de $560 \mathrm{~m}^{2}$, con el objetivo de definir los límites del sitio (Santiago 2009).

Las ocupaciones registradas en la localidad La Arcillosa son efímeras, pero se destaca la recurrencia de las mismas durante el Holoceno medio. Sin embargo esta reiteración en el uso del espacio no está acotada a un locus específico, sino que se produjo en distintos sectores del paisaje, próximos entre si.

El sitio RCh1 (Figura 1), se ubica en la margen derecha del río homónimo, aproximadamente 1,5 km al norte de LA2. Es un conchero sepultado por sedimentos coluviales; la lente de valvas se extiende por $8 \mathrm{~m}$ y tiene una potencia de unos $40 \mathrm{~cm}$ (Santiago et al. 2007). Una prospección con GPR permitió definir los límites del conchero (Santiago 2009) y a partir de ello se planteó la superficie a excavar.

Un primer análisis de los materiales arqueológicos recuperados en RCh1 se presentó en Santiago et al. (2007) y un estudio más detallado del sitio y los materiales 
se encuentra en Santiago (2013). Su excavación alcanzó $3 \mathrm{~m}^{2}$, recuperándose más de 1600 artefactos líticos y 10728 restos óseos e identificando una lente de fogón de $60 \mathrm{~cm}$ de diámetro aproximado (Santiago et al. 2007, Santiago 2013).

La estratigrafía fue definida en cuatro unidades, donde la tercera unidad -de origen antrópico- es un conchero de matriz arenosa y con lentes de arena intercalados, de no más de $40 \mathrm{~cm}$ de espesor. El nivel inferior está conformado por arenas grises estratificadas, asignables a un sedimento eólico de arenas de playa retrabajado (Santiago 2013).

Para el momento de ocupación el nivel del mar estaba por encima del nivel actual, por lo tanto el sitio estaba en contacto directo con la línea de costa del Holoceno medio. Las arenas subyacentes al conchero contenían fragmentos de valvas que fueron datados en $5918 \pm 44$ ARCP (Santiago et al. 2007). En base a los fechados y la posición estratigráfica del depósito arqueológico, la ocupación del sitio es asignable al máximo transgresivo del Holoceno (Santiago 2013).

Ambos sitios comparten las fuentes de abastecimiento de materia prima lítica. Estas se presentan en forma de depósitos de rodados distribuidos con relativa homogeneidad en el paisaje, producto de la acción glacial, glacifluvial y marina (cordones litorales) durante el Cuaternario. Por lo tanto, en todos los casos se trata de fuentes secundarias. Las materias primas representadas en los conjuntos son distintas variedades de riolita, toba silicificada ${ }^{1}$, basalto, sedimentita, cuarzo, granodiorita y otras rocas que no han podido ser identificadas.

\section{Metodología}

Los materiales considerados en este trabajo provienen de la totalidad de la superficie excavada en RCh1 ( $n=1606)$, y de las excavaciones de LA2 ( $n=931)$ (Tabla 2). Para este último sitio también se incluyeron en el análisis los artefactos líticos recuperados a través de recolecciones superficiales, en zonas inmediatamente adyacentes al depósito excavado. Esto se debe a que, como se mencionó previamente, existen distintas evidencias que permiten considerar que ambos tipos de registro (en posición estratigráfica y superficial) fueron parte de un mismo contexto (Salemme et al. 2007a; Santiago 2013). Se analizaron la totalidad de los núcleos y artefactos formatizados hallados en ambos sitios y en cuanto a los desechos, se seleccionó a través de un muestreo aleatorio simple el 55\% del total recuperado en RCh1 $(n=860)$ y LA2 ( $n=447)$.

Los artefactos líticos fueron clasificados en tres categorías: núcleos, desechos y artefactos formatizados (Aschero 1975). En todos los casos se registraron sus dimensiones,

\footnotetext{
${ }^{1}$ En otros trabajos esta materia prima fue denominada calcedonia, en un sentido amplio (Salemme et al. 2007a, Santiago 2013).
}

forma base, tipo de materia prima, reserva de corteza y peso (Ahler 1989; Andrefsky 1998; Aschero 1975; Orquera y Piana 1986; Paulides 2006; Shott 1994). Además, se relevaron atributos específicos para cada una de las categorías artefactuales mencionadas.

Para el análisis de los núcleos se siguieron los lineamientos generales propuestos por Paulides (2006). Se evaluó el tipo de núcleo, la cantidad mínima de extracciones, el tipo de plataforma y su estado. Para estimar el tamaño de los núcleos se siguió la propuesta de Andrefsky (1998:139) de calcular la dimensión lineal máxima (DML), que se trata de la longitud máxima de un núcleo multiplicada por su peso.

En los desechos se consideró el aspecto de la cara dorsal, tipo de bulbo y talón, presencia de rastros complementarios del talón, labio, estrías y curvatura (Aschero 1975; Bellelli et al. 1985-1987; Orquera y Piana 1986). También se incorporaron categorías específicas de productos bipolares, como el tipo de bulbo negativo y talón astillado (Bonomo 2004). Además se registraron los tipos de fractura y se calculó un índice de fragmentación por materia prima (Hiscock 2002).

Para artefactos formatizados se contemplaron: opciones técnicas (Pal 2012), anchura, ubicación respecto a la cara de la pieza (Aschero 1975), ubicación de acuerdo al sector del borde, forma, continuidad, profundidad y tipo de lascados (Orquera y Piana 1986). Respecto a los bordes potencialmente activos se registró su forma general, longitud, ángulo del bisel y forma de la arista (Orquera y Piana 1986).

\section{Resultados}

\section{Composición artefactual}

Núcleos

En LA2 el número de núcleos es proporcionalmente mayor al de RCh1 (Tablas 2 y 3). La forma base en todos los casos son rodados. Para el caso particular de RCh1, 5 de los núcleos corresponden a fragmentos (Tabla 3) entre los cuales se corroboró relación de ensamblaje. Los tipos más frecuentes en RCh1 son aquellos con lascados aislados seguidos por núcleos sobre rodados o nódulos testeados (NSR o NT), residuales (sin formas tipificantes), con lascados selectivos y otras formas representadas por un único ítem. En LA2 se registra una mayor variedad de formas, entre las que predominan aquellas con lascados selectivos y residuales, seguidas por núcleos con lascados aislados, poliédricos parciales, discoidales irregulares, sobre rodados (NSR o NT), bifaciales y globulosos. En un único caso se identificó la forma pseudoprismática (Tabla 3).

Cabe destacar la presencia en ambos sitios de núcleos preparados mediante extracciones centrípetas para la obtención de una lasca preferencial, una modalidad 


\begin{tabular}{|c|c|c|c|c|}
\hline Categoría Artefactual & $\begin{array}{r}\text { LA2 } \\
10 \mathrm{exc} .\end{array}$ & $\begin{array}{r}\text { LA2 } \\
20 \text { exc. }\end{array}$ & RCh 1 & TOTAL \\
\hline Artefacto formatizado por talla & 7 & 15 & 11 & 33 \\
\hline Artef. formatizado por picado/abrasión & 3 & 0 & 0 & 3 \\
\hline Lasca & 288 & 390 & 925 & 1603 \\
\hline M icrolasca & 32 & 80 & 374 & 486 \\
\hline Desecho indiferenciado & 13 & 9 & 266 & 288 \\
\hline Núcleo & 45 & 24 & 25 & 94 \\
\hline Percutor & 3 & 0 & 1 & 4 \\
\hline Nódulo & 17 & 2 & 1 & 20 \\
\hline Ecofacto & 0 & 3 & 3 & 6 \\
\hline Total & 408 & 523 & 1606 & 2537 \\
\hline
\end{tabular}

Tabla 2. Composición artefactual de los sitios arqueológicos LA2 y RCh1.

Table 2. Artefactual composition of LA2 and RCh1 archaeological sites. técnica semejante a Levallois (ver Figura 3). La presencia de núcleos y lascas Levallois ya se había registrado en dos sitios arqueológicos en el sudeste de la isla, Estancia Viamonte (Vallin 1992) y Rancho Donata (Nami 1992). Este último sitio correspondería cronológicamente al Holoceno tardío. También Morello (2005) describió la presencia de esta técnica en la península de Juan Mazía y en el sitio Monmouth 20 (ca. 5500 años ARCP; Morello et al 2009b). En este sentido, los dos hallazgos presentados en este trabajo, se suman a las evidencias del uso de esta técnica durante el Holoceno medio.

Del total de núcleos, 6 fueron también utilizados como percutores (2 en LA2 y 4 en RCh1). En RCh1, además, se recuperó un percutor sin evidencias de lascado. En ambos sitios se registraron nódulos (ver Tablas 2 y 3) que no presentan evidencias ni de lascados ni de uso como percutor; por las características de los sitios - ambos concheros - la presencia de estos ítems se explica solo

\begin{tabular}{|c|c|c|c|c|}
\hline \multirow{2}{*}{ Tipo de Núcleo } & \multicolumn{2}{|c|}{ LA2 } & \multicolumn{2}{|c|}{ RCh1 } \\
\hline & $\mathrm{N}$ & $\%$ & $\mathrm{~N}$ & $\%$ \\
\hline Bifacial & 2 & 2.9 & 0 & 0 \\
\hline Discoidal & 0 & 0.0 & 1 & 4 \\
\hline Discoidal irregular & 6 & 8.7 & 0 & 0 \\
\hline Globuloso & 2 & 2.9 & 0 & 0 \\
\hline Lascados aislados & 11 & 15.9 & 5 & 20 \\
\hline Lascados selectivos & 19 & 27.5 & 2 & 8 \\
\hline NSR o NT & 3 & 4.3 & 4 & 16 \\
\hline Poliédrico parcial & 7 & 10.1 & 1 & 4 \\
\hline Pseudopiramidal & 0 & 0.0 & 1 & 4 \\
\hline Pseudprismatico & 1 & 1.4 & 0 & 0 \\
\hline Residual & 16 & 23.2 & 4 & 16 \\
\hline Levallois & 1 & 1.4 & 2 & 8 \\
\hline Indet (fragmento) & 1 & 1.4 & 5 & 20 \\
\hline Plataforma & $\mathrm{N}$ & $\%$ & $\mathrm{~N}$ & $\%$ \\
\hline Natural & 21 & 30.4 & 11 & 44 \\
\hline Natural y preparada & 1 & 1.4 & 0 & 0 \\
\hline No observable & 25 & 36.2 & 10 & 40 \\
\hline Preparada & 22 & 31.9 & 4 & 16 \\
\hline Estado & $\mathrm{N}$ & $\%$ & $\mathrm{~N}$ & $\%$ \\
\hline Agotado & 15 & 21.70 & 5 & 20 \\
\hline Fracturado & 5 & 7.20 & 7 & 28 \\
\hline No agotado & 49 & 71.00 & 13 & 52 \\
\hline TOTAL & 69 & 100 & 25 & 100 \\
\hline
\end{tabular}

Tabla 3. Tipos de núcleos reconocidos en los conjuntos de LA2 y RCh1.

Table 3. Types of nucleus identified in RCh1 and LA2 assemblages. por vía antrópica. En cuanto al tipo de plataformas es destacable el porcentaje de plataformas preparadas en los núcleos de LA2 respecto de lo observado en RCh1, en donde predominan las plataformas naturales (Tabla 3). Respecto al estado de los núcleos enteros se observa un predominio de la categoría no agotados en ambos contextos, que alcanza el $52 \%$ en RCh1 $(n=13)$ y el $71 \%$ en LA2 $(n=49)$.

\section{Artefactos formatizados}

En LA2 se analizaron veintidós artefactos formatizados elaborados por percusión sobre lascas primarias, secundarias y núcleos. En el sitio también se recuperaron tres artefactos elaborados mediante picado/pulido y abrasión, entre los que se incluyen dos bolas con surco y un mortero, que han sido descriptos en detalle en otras publicaciones y por este motivo no son considerados en este acápite. En este sitio se observó mayor variedad de materias primas seleccionadas para la formatización, registrándose toba silicificada $(n=10)$, riolita $(n=7)$, basalto $(n=4)$ y una roca que no pudo ser determinada $(n=1)$. No se pudo relevar la totalidad de los atributos en siete artefactos, ya que se encontraban fracturados. Los lascados son mayormente unifaciales directos, aunque también se registró retalla bifacial en tres artefactos (Figura 2). En dos de ellos, la bifacialidad se limita a uno de los bordes retocados en donde se combinaron retalla directa con retoque y retalla inversa. El segundo de los artefactos bifaciales, en cambio, presenta retalla perimetral en ambas caras de la pieza.

En cuanto a las opciones técnicas, las categorías mejor representadas son los filos largos retocados $(n=8)$ seguidos por artefactos compuestos $(n=5)$, lascas con retoque sumario $(n=2)$, filo corto retocado $(n=1)$ y doble filo largo retocado $(n=1)$. En base al ancho y profundidad de los lascados se registraron predominantemente retoque marginal y ultramarginal $(n=16)$, seguido por retalla $(n=10)$ y microrretoque $(n=8)$. Los tipos de retoque presentes en el conjunto son: semicircular regular $(n=8)$, semicircular irregular $(n=6)$, sub-paralelo $(n=4)$, escalonado $(n=3)$, escamoso irregular $(n=2)$ y paralelo $(n=1)$. Respecto a los ángulos de los filos, los más abundantes son los 
abruptos $(n=16)$, seguidos por agudos $(n=14)$ y muy oblicuo $(n=1)$. Los tipos de aristas presentes son irregular $(n=11)$, recta $(n=7)$, sinuosa $(n=5)$ y ondulada $(n=1)$. La forma general del borde activo más frecuente es convexa $(n=14)$ y en menor medida se identificaron formas en arco $(n=4)$, cóncavas $(n=3)$, rectas $(n=2)$ y sinuosa $(n=1)$. Los tamaños presentes en el conjunto son mediano $(n=12)$, grande $(n=6)$ y chico $(n=4$, en este último caso se trata de fragmentos). Los módulos anchura espesor son poco espeso $(n=7)$, espeso $(n=12)$ y muy espeso $(n=3)$.

En RCh1 se recuperaron 11 artefactos formatizados, los cuales fueron elaborados principalmente mediante lascados unifaciales directos sobre lascas con resto cortical e internas de toba silicificada $(n=7)$ y riolita $(n=4)$ (Figura 3). También se registró la presencia de retalla bifacial en tres ítems manufacturados sobre diferentes tipos de formas base (lasca primaria, lasca secundaria y artefacto sobre núcleo). Estos artefactos bifaciales poseen en común la presencia de más de un borde retocado por artefacto, pero la retalla bifacial se restringe, en todos los casos, solo a uno de sus bordes.

Las opciones técnicas predominantes, para todos los artefactos formatizados, son los filos largos retocados $(n=5)$ seguidos por filos cortos retocados $(n=3)$, artefactos compuestos $(n=2)$ y doble filo largo retocado $(n=1)$. De acuerdo al ancho de los lascados y su profundidad se identificaron principalmente retoque ultramarginal y marginal $(n=7)$, seguido de la retalla $(n=5)$ y el microrretoque $(n=4)$. Los tipos de retoque presentes en el conjunto son: semicircular irregular $(n=4)$, sub-paralelo $(n=3)$, semicircular regular $(n=2)$, escamoso irregular $(n=1)$ y escalonado $(n=1)$. En cuanto a los ángulos de los filos, predominan muy oblicuos $(n=6)$ seguidos por los abruptos $(n=5)$ y agudos $(n=5)$. Los tipos de aristas presentes son: rectas $(n=10)$, irregulares $(n=2)$, onduladas $(n=2)$ y sinuosas $(n=2)$. La forma general del borde activo más frecuente es la convexa $(n=12)$ y en menor medida están presentes las formas en $\operatorname{arco}(n=2)$, cóncava $(n=1)$ y recta $(n=1)$.

Los tamaños presentes en el conjunto son mediano $(n=9)$ y grande $(n=2)$, mientras que los módulos anchura/espesor registrados son poco espeso $(n=7)$ y espeso $(n=4)$.

\section{Desechos de talla}

Desechos indiferenciados, lascas y microlascas representan el $97,45 \%$ de la composición artefactual en el sitio RCh1 y el 87,22\% en LA2 (Tabla 2). La tabla 4 resume las principales variables relevadas para esta categoría artefactual en la muestra que abarca el 55\% de los desechos de ambos conjuntos.

Para considerar los diferentes tipos de materias primas identificadas en cada conjunto se tuvieron en cuenta las lascas enteras, fracturadas y desechos indiferenciados. Tanto en RCh1 como en LA2 predomina la riolita seguida

por toba silicificada y el basalto, que en RCh1 está presente en un único ítem. En LA2 se registró una mayor variedad de materias primas, aunque escasamente representadas, que incluyen cuarzo, sedimentita y granodiorita.
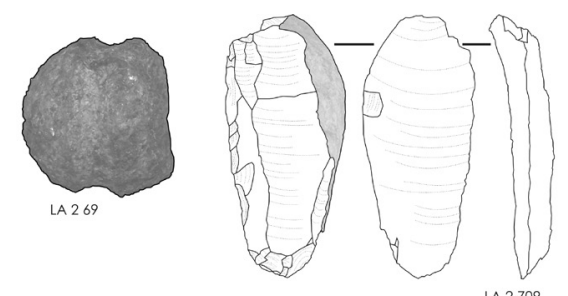

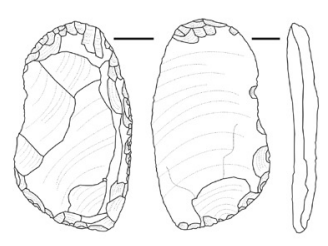

LA 2973

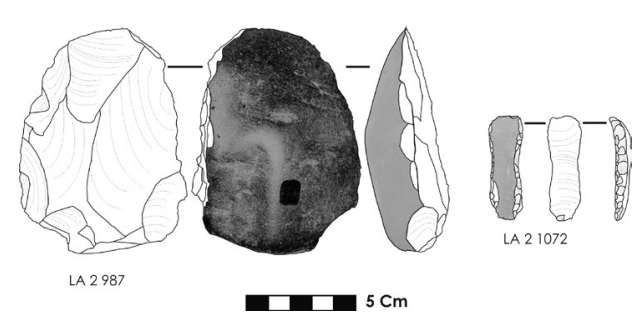

Figura 2. Artefactos formatizados del sitio LA2.

Figure 2. Retouched artifacts from LA2 site.
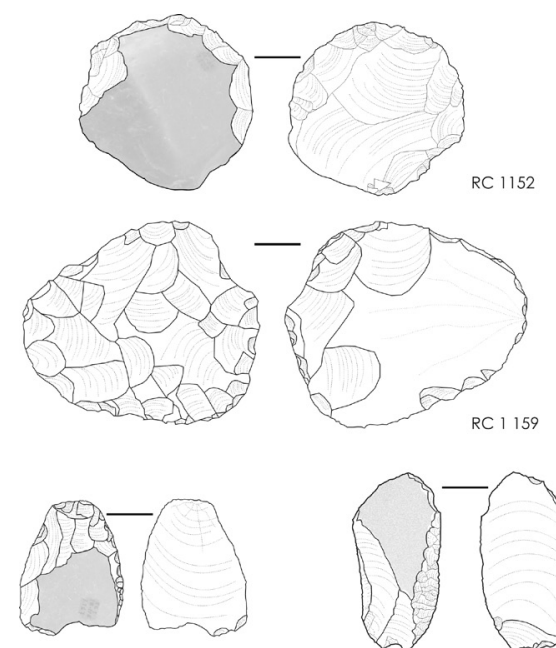

RC 1167
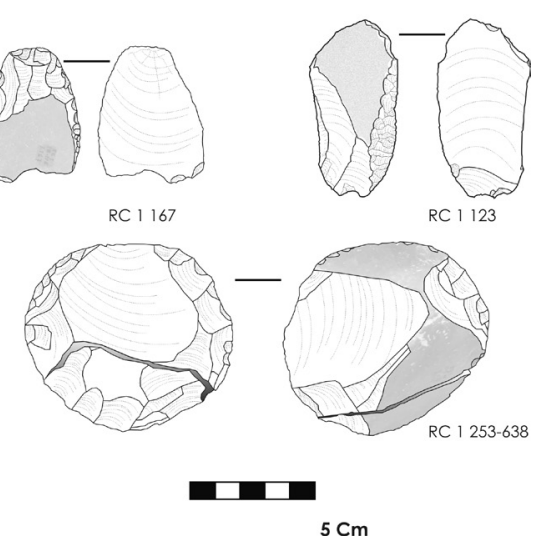

Figura 3. Artefactos formatizados y núcleos Levallois (RC 1152 y 253638) del sitio RCh1.

Figure 3. Retouched artifacts and Levallois cores (RC 1152 y 253-638) from RCh1 site. 
Respecto a la reserva de corteza, en ambos sitios predominan las lascas internas, seguidas por aquellas con menos del $50 \%$ de corteza en su cara dorsal. Las lascas primarias también están presentes, aunque en un menor porcentaje. Los tamaños identificados en cada sitio presentan diferencias destacables entre los conjuntos. En RCh1 más de la mitad de la muestra está compuesta por desechos de tamaño chico, seguidos por artefactos de tamaño muy chico y mediano. La categoría grande abarca un porcentaje cercano al $1 \%$ y la categoría muy grande está ausente. En LA2, en cambio, los tamaños muy chico, chico y mediano poseen casi idéntica representación, aproximadamente el $30 \%$ en cada caso. La categoría grande posee un mayor número de ítems en comparación con RCh1 y la categoría muy grande, aunque escasa, está presente en LA2.

Sobre la base de la forma y relación de los negativos de lascados presentes en la cara dorsal se identificaron diversos tipos de lascas. En ambos sitios predominan ampliamente las lascas angulares mientras que los desechos sin lascados y con aristas paralelas tienen una escasa representación. La presencia de lascas de arista única longitudinal también es semejante en ambos conjuntos. En RCh1 hay una mayor presencia de lascas llanas que en LA2 y esta relación se invierte respecto a las lascas en cresta. Los tipos de talones más abundantes en ambos sitios son los lisos y los menos representados, con porcentajes inferiores al 3\%, son los naturales y facetados (Tabla 4). Los talones diedros poseen proporciones muy semejantes en ambos sitios, levemente inferiores al $5 \%$. Las mayores diferencias se observan en los talones astillados, que en RCh1 conforman alrededor del 10\% de las lascas con talón mientras que en LA2 no alcanzan el $1 \%$, y en los talones lisos naturales, más abundantes en LA2 que en RCh1. En ambos sitios se registró la presencia de talones preparados (RCh1: 7,91\%, $n=68$; LA2: 15,88\%, $\mathrm{n}=71$ ) y abradidos (RCh1: 1,28\%, $\mathrm{n}=11$; LA2: 2,01\%, $n=9)$. Los tipos y frecuencias de bulbos identificados en RCh1 y LA2 muestran tendencias semejantes, en donde predominan los difusos (RCh1: 9,07\%, $n=78$; LA2: 5, 15\%, $\mathrm{n}=23$ ), seguidos por los pronunciados (RCh1: $4,42 \%$, $\mathrm{n}=38$; LA2: $4,92 \%, \mathrm{n}=22$ ) y negativos (RCh1: $2,33 \%$, $n=20 ;$ LA2: $0,22 \%, n=1)$. En cuanto a la presencia de labio, en RCh1 se logró identificar en un 9,77\% ( $n=84)$ mientras que en LA2 está presente en un 8,95\% $(n=40)$. Otra variable indicadora de aspectos técnicos, la presencia de curvatura, es escasa tanto en $\operatorname{RCh} 1(6,51 \%, n=56)$ como en LA2 $(6,49 \%, n=29)$.

\section{Materias primas, fragmentación y peso}

Los mismos tipos de materia prima están presentes en ambos conjuntos, aunque en distintas proporciones (para detalle de desechos de talla ver Tabla 4; para núcleos ver Tabla 5). Para establecer la abundancia original de cada materia prima fue necesario considerar aspectos vinculados a la integridad de estos conjuntos, ya que algunos tipos de roca podrían estar sobrerrepresentados al ser afectados de modo diferencial por fragmentación. Con este objetivo se describieron los diferentes tipos de fractura (Tabla 4) y luego se procedió a calcular el índice de fractura (Hiscock 2002). Para estimar el número mínimo de lascas se consideraron las materias primas más abundantes en cada sitio: riolita y toba silicificada en RCh1 y riolita, toba silicificada y basalto en LA2. Esto se debe a que el número de ítems líticos en las restantes materias primas es demasiado bajo como para poder evaluar su integridad. En LA2 riolita y toba silicificada presentan índices muy semejantes (1,82 y 1,83, respectivamente), por lo que la fragmentación no puede generar una sobrerrepresentación a nivel intrasitio entre estas dos materias primas; el basalto, a pesar de poseer el índice de fragmentación más alto (2), es la materia prima menos representada considerando su frecuencia absoluta. En RCh1 el índice de fragmentación de la riolita $(1,73)$ es levemente mayor al de la toba silicificada $(1,58)$, sin embargo se considera que esta diferencia no afecta de modo significativo su representación en el conjunto. En síntesis, el grado de fragmentación en los desechos de ambos sitios sugiere que ésta no incide de forma determinante en la representación diferencial de las materias primas identificadas.

Una variable que permite evaluar el volumen aportado por cada materia prima en los sitios, y que además no se ve afectada por el grado de fragmentación, es el peso. Para su medición se tuvieron en cuenta los núcleos y artefactos formatizados, así como la muestra, previamente descripta, que corresponde a la mitad de los desechos recuperados en cada sitio (Figura 4). En todos los casos esta variable se midió con una balanza de precisión Mettler modelo PC4400. Los valores para cada tipo de materia prima registrados en cada sitio fueron:

-LA2: riolita: 19307,64 g ( $n=329)$; toba silicificada: 14041,08 g ( $n=154) ;$ basalto: 666,09 g ( $n=36)$; sedimentita: 25,61 g ( $n=7)$; cuarzo: 14,55 g ( $n=7)$; granodiorita: 106,26 $\mathrm{g}(\mathrm{n}=2)$ y materias primas indeterminadas: $511,75 \mathrm{~g}(\mathrm{n}=3)$. -RCh1: riolita: $5299,49 \mathrm{~g}(\mathrm{n}=483)$; toba silicificada: $5262,54 \mathrm{~g}(\mathrm{n}=410)$ y basalto: $5,13 \mathrm{~g}(\mathrm{n}=3)$.

Si discriminamos a los núcleos por sitio y por materia prima observamos que en LA2 los ítems de riolita aportan un total de 14463,4 g (promedio: 498,74 g) mientras que los de toba silicificada suman un peso de 12785,3 g (promedio: $336,4 \mathrm{~g}$ ) y los núcleos de materia primas indeterminadas pesan 506,8 g (promedio de 253,4 g). En RCh1 los núcleos de riolita poseen un peso total de 2286,8 9, (promedio: $207,9 \mathrm{~g}$ ) y los núcleos de toba silicificada pesan, en conjunto, 3311,67 g (promedio: 236,5 g).

Respecto a los artefactos formatizados existe una importante diferencia entre los artefactos compuestos y el resto de los artefactos que representan otras opciones técnicas (Figura 4C). En RCh1 el total de artefactos compuestos $(n=2)$ pesan $162,06 \mathrm{~g}$, con un promedio de 


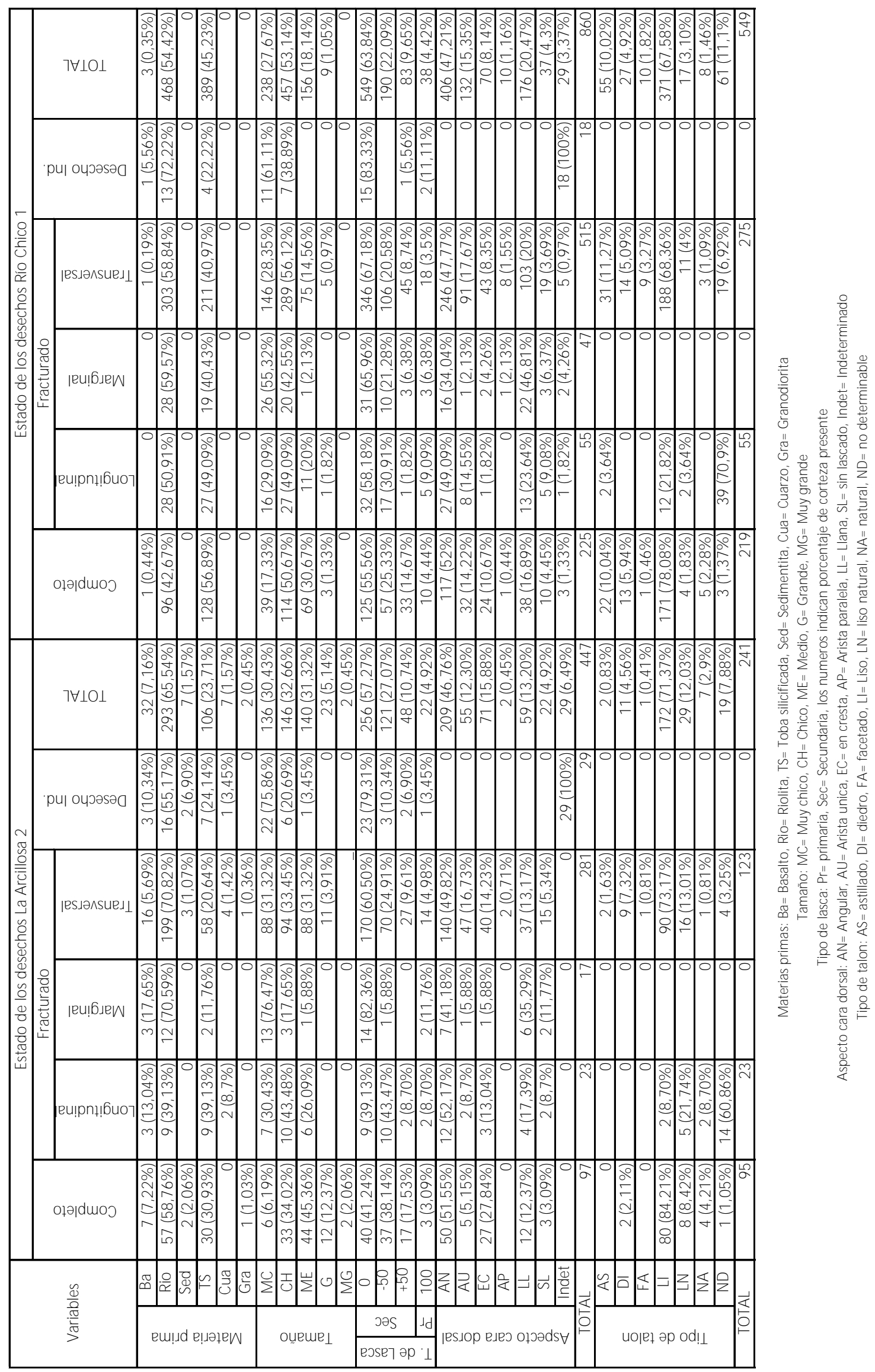

Tabla 4. Características tecnomorfológicas relevadas en los desechos de LA2 y RCh1.

Table 4. Technomorphological characteristics of flaking debris from LA2 y RCh1. 
$81,03 \mathrm{~g}$, mientras que el resto de las categorías técnicas $(n=9)$ suman en conjunto un peso de 341,56 g, con un promedio de 37,95 g. En el caso de LA2 esta tendencia se registra de forma más pronunciada, ya que el peso de los artefactos compuestos ( $n=5)$ es de 1085,61 g con un promedio de 217,12 g. El total de las demás categorías técnicas $(n=17)$ poseen un peso de $409,37 \mathrm{~g}$, con un promedio de 24,08 g. Es decir que en ambos sitios los artefactos compuestos fueron elaborados sobre soportes que poseen un peso mayor en comparación al resto de los artefactos que representan otras categorías técnicas.

Si consideramos solo el conjunto de los desechos e incluimos todas las materias primas presentes en cada sitio (Figura 4B), el rango de valores en RCh1 oscila entre 0,17 g y 175,5 g; mientras que en LA2 el valor mínimo es 0,03 g y el valor máximo 323,1 g. En LA2 el rango de valores es más amplio, registrándose mayor cantidad de piezas con pesos que superan los $100 \mathrm{~g}$. Es decir, en LA2 la mayor parte del volumen de los desechos es aportado por pocas piezas con pesos mayores a los $100 \mathrm{~g}$ mientras que en RCh1 el mayor volumen es aportado por numerosos desechos con pesos inferiores a los $5 \mathrm{~g}$.

\section{Reserva de corteza}

Del análisis de esta variable surge que ambos sitios presentan una proporción mayor de materiales con ausencia de corteza. Esto podría estar vinculado a tres aspectos principales: (1) el tamaño de los rodados utilizados como nódulos iniciales - los artefactos procedentes de rodados pequeños tenderán a conservar mayor proporción de corteza en sus superficies-, (2) el grado de explotación que recibieron estos nódulos, o bien (3) el tipo de actividades que se realizaron en cada sitio.

En relación al primer aspecto, como se demostró en el apartado anterior, la proporción de artefactos grandes y muy grandes es baja, aun incluyendo los núcleos. En RCh1 se registró un predominio de materiales de tamaño chico; sin embargo, a partir del cálculo de MLD, el tamaño de los núcleos no muestra un patrón definido al comparar tanto entre conjuntos como entre materia prima. La diferencia en las proporciones de presencia de corteza en ambos sitios no es explicable, entonces, por el tamaño de los nódulos seleccionados y posteriormente tallados en cada sitio.

En cuanto al grado de explotación, como se mencionó, más del $50 \%$ de los núcleos no están agotados en los dos sitios. En relación a la reserva de corteza, más de la mitad en ambos conjuntos preservan corteza en el 50\% o más de su superficie, en tanto que la mayor parte de los núcleos restantes conservan solo $25 \%$, siendo escasos los núcleos sin corteza en LA2 o incluso ausentes en RCh1.

Al analizar la reserva de corteza en relación a los tipos de roca (Tabla 5), la mayor cantidad de núcleos de riolita en LA2 y toba silicificada en RCh1 presentan reserva de corteza en el $25 \%$ de su superficie (o incluso ausencia de corteza en LA2), sugiriendo un mayor grado de explotación de estas materias primas.

Para evaluar el tipo de actividades que se desarrollaron en cada sitio es necesario considerar la información aportada por el análisis de los desechos y núcleos en forma conjunta. Tanto en RCh1 como en LA2 las lascas internas son la categoría mejor representada, seguidas por lascas con resto cortical, lascas primarias de descortezamiento y lascas iniciales (ver porcentajes Tabla 4). Por otra parte, como ya se mencionó, en ambos sitios se recuperaron núcleos con distinto grado de explotación. Esta información en conjunto puede interpretarse como evidencia de la presencia de todas las etapas de la cadena operativa, a través de la cual se produjo una progresiva reducción de núcleos in situ.

Como la reserva de corteza está estrechamente vinculada al tamaño de los desechos, en ambos sitios existe una mayor representación de los tamaños muy chico y chico en lascas internas (RCh1: chico: 32,91\%, $\mathrm{n}=283$ y muy chico: $22,09 \%, n=190$; LA2: chico $19,68 \%, n=88$, muy chico $24,61 \%, n=110)$. En las lascas con resto cortical se observa la misma tendencia en RCh1 (chico 12,32\%, $\mathrm{n}=107$ y muy chico $3,22 \%, \mathrm{n}=28$ ) mientras que en LA2 existe un predominio de los tamaños medianos (13,64\%, $\mathrm{n}=61)$ seguidos por la categoría chico $(7,6 \%, \mathrm{n}=34)$. A medida que el porcentaje de corteza aumenta, también se registra un aumento en el tamaño de las lascas, tanto en aquellas con más del $50 \%$ de corteza (RCh1: chico $5 \%, n=43$, mediano 3,02\%, $n=26$; LA2: chico 3,13\%, $\mathrm{n}=14$, mediano $5,1 \%, \mathrm{n}=23$ ) como en las lascas primarias (RCh1: chico 2,79\%, n=24, mediano 1,04\%, n=9). En este último caso, LA2 presenta una tendencia diferente, con una representación más abundante de lascas primarias de tamaño chico $(2,23 \%, n=10)$ y muy chico $(1,78 \%, n=8)$, que incluyen fragmentos de pequeños rodados de cuarzo y pequeñas placas de corteza de otras materias primas, como basalto, riolita y toba silicificada.

En síntesis, tanto en LA2 como en RCh1 los desechos se vuelven más numerosos y pequeños a medida que avanza la reducción, si bien siempre se registra una importante presencia de los tamaños chico y/o muy chico. Esto se debe a que los sub-productos de menores dimensiones son producidos a lo largo de toda la secuencia de talla, desde estadíos iniciales hasta el retoque o formatización final de formas base. Por otra parte la baja representación de lascas grandes y muy grandes, en especial en RCh1, parece estar relacionado con los tamaños de los núcleos.

\section{Discusión}

En relación a los conjuntos y su integridad

Aspectos destacables y comunes en los dos contextos 


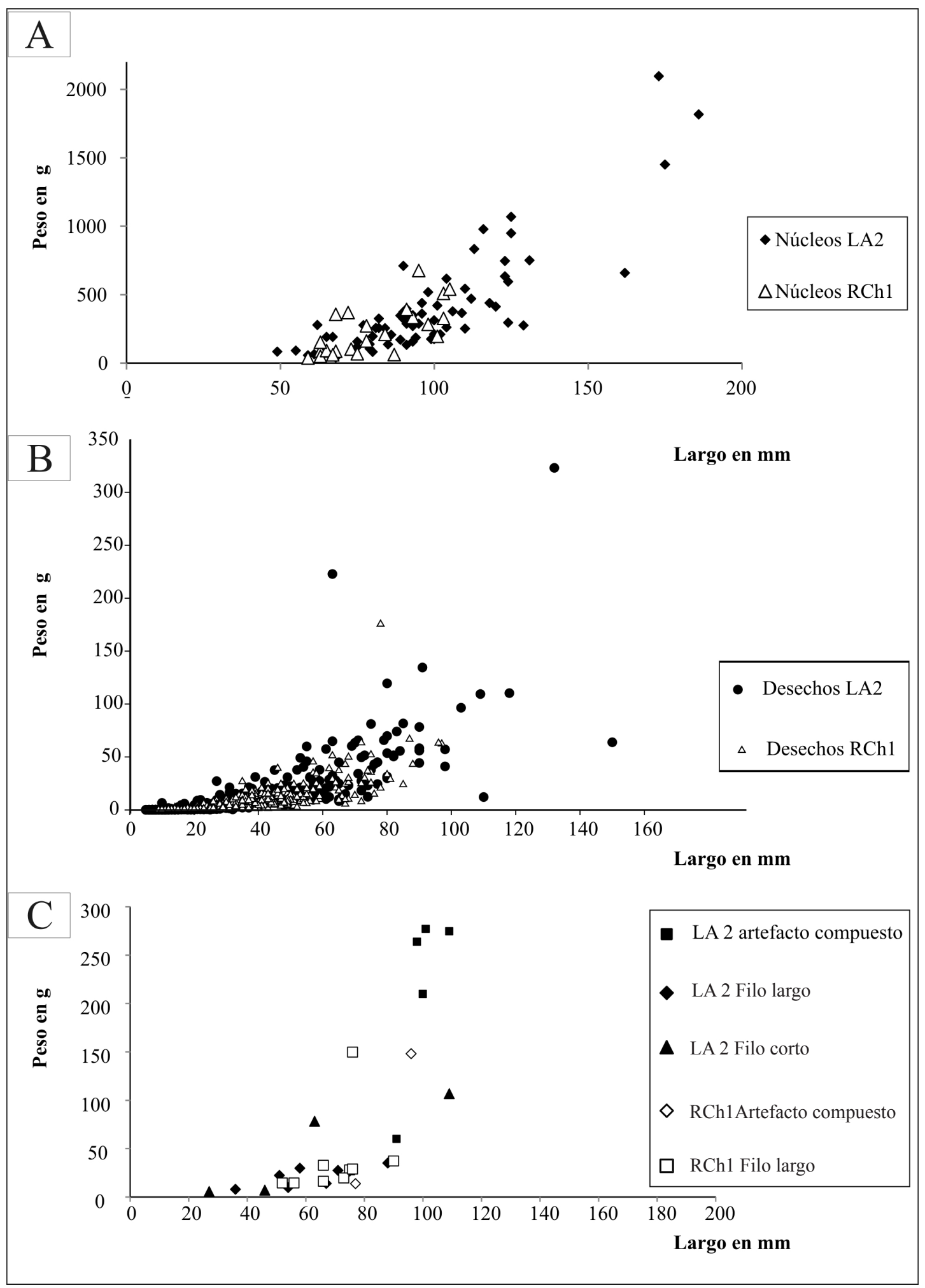

Figura 4. Distribución de núcleos, desechos y artefactos formatizados de acuerdo a las variables peso y largo.

Figure 4. Distribution of cores, debris and retouched artifacts according to their weight and length.

presentados son la ausencia de puntas de proyectil y la presencia de filos largos retocados y lascas retocadas, así como retalla bifacial en artefactos con formatización secundaria. No obstante, en ambos conjuntos este tipo de artefactos es muy escaso en relación al resto de las categorías artefactuales, particularmente los desechos de talla, lo cual es más marcado en el caso de RCh1.

El análisis de desechos, categoría artefactual predominante en RCh1 y LA2, también pone de manifiesto características 


\begin{tabular}{|c|c|c|c|c|c|c|c|c|c|}
\hline \multirow{3}{*}{ \% Corteza } & \multicolumn{4}{|c|}{ LA2 } & \multicolumn{4}{|c|}{ RCh1 } & \multirow{3}{*}{ TOTAL } \\
\hline & \multicolumn{2}{|c|}{ Riolita } & \multicolumn{2}{|c|}{ T. silicificada } & \multicolumn{2}{|c|}{ Riolita } & \multicolumn{2}{|c|}{ T. silicificada } & \\
\hline & $\mathrm{N}$ & $\%$ & $\mathrm{~N}$ & $\%$ & $\mathrm{~N}$ & $\%$ & $\mathrm{~N}$ & $\%$ & \\
\hline 0 & 4 & 13.8 & 0 & 0 & 0 & 0 & 0 & 0 & $r^{\prime}$ \\
\hline 25 & 11 & 37.9 & 10 & 26.3 & 3 & 27.27 & 7 & 50.00 & 31 \\
\hline 50 & 9 & 31.0 & 21 & 55.3 & 5 & 45.45 & 2 & 14.29 & 37 \\
\hline 75 & 4 & 13.8 & 7 & 18.4 & 3 & 27.27 & 5 & 35.71 & 19 \\
\hline 100 & 1 & 3.5 & 0 & 0 & 0 & 0 & 0 & 0.00 & 1 \\
\hline TOTAL & 29 & 100 & 38 & 100 & 11 & 100 & 14 & 100 & 92 \\
\hline
\end{tabular}

Tabla 5. Tipos de materia prima más abundantes y porcentajes de corteza de los núcleos de LA2 y RCh1

Table 5. Types of most abundantraw materials and cortex percentage of nucleus from LA2 and RCh1 técnicas presentes en ambos sitios. Si tenemos en cuenta los tipos de talones identificados, un aspecto en común es la mayor proporción de talones lisos en los dos conjuntos, lo cual indica la preponderancia de manufactura a través de percusión directa (Valverde 2003). Sin embargo, otros tipos de talones muestran diferencias entre los sitios. En LA2 hay un mayor porcentaje de talones lisos naturales, que podrían indicar un énfasis en las primeras etapas de adecuación de los núcleos o formas base con alto porcentaje de corteza. Por otra parte en RCh1 hay una mayor presencia de talones astillados así como de bulbos difusos, que en conjunto estarían indicando un mayor empleo de talla bipolar.

Los rasgos complementarios del talón, especialmente la preparación del mismo, está presente en una mayor proporción tanto en los desechos como en los núcleos de LA2. Si además se tiene en cuenta que en este sitio se registró un mayor porcentaje de tamaños medianos, grandes y muy grandes, puede sugerirse que en LA2 se produjo una mayor inversión de trabajo orientado hacia la producción de formas base. En cuanto al tipo de negativos de lascados es interesante señalar que el porcentaje de lascas de arista única y en cresta, que considerados en forma conjunta alcanzan un $29,63 \%$ en LA2 y $22,93 \%$ en RCh1, indican el uso intencional de las aristas como eje de la fuerza generada por percusión, lo que permite un mayor control de la forma en la extracción de lascas.

Otro aspecto a tener en cuenta es la presencia de bifacialidad, que fue identificada en algunos artefactos formatizados recuperados en los dos sitios. La escasa presencia de los rasgos que permiten identificar esta modalidad de talla en los desechos, como curvatura, talones facetados y labio (Bellelli y Kligmann 1996), indican una baja incidencia de esta técnica en ambos conjuntos. Los artefactos formatizados presentes en los sitios permiten reafirmar lo observado en los desechos, debido a que existe un claro predominio de lascados unifaciales. Además la formatización bifacial se restringe en todos los casos a algunos de los bordes activos de los artefactos y no se expande a toda la pieza.

En relación a las materias primas no se observó diferencia en los tipos de roca registrados, los cuales son coherentes con la composición de materias primas registrada en otros sitios a nivel regional (Borrazzo 2012; Oría 2012; Santiago 2013). En general se observa un perfil similar para los índices de fragmentación de los distintos tipos de roca en ambos sitios, por lo que consideramos que la diferencia en las proporciones de las materias primas presentes en los sitios no puede ser explicada por el grado de fragmentación de los artefactos. Por otra parte es necesario considerar el alto número de desechos fracturados. Es esperable registrar un número alto de fracturas en las etapas iniciales de adecuación de núcleos, donde, para lograr su descortezamiento y regularización para la extracción de formas base, se generan excesos de fuerza que provocan la rotura de los artefactos líticos (Doelman 2002). Pero como se mencionó antes, los estadíos iniciales no están representados en forma diferencial respecto a otras etapas de la secuencia de talla, y las fracturas están presentes en todos los tamaños y tipos de lascas. Además el alto número de fracturas no puede explicarse en base a propiedades mecánicas de las materias primas utilizadas, ya que los índices son semejantes en los diferentes tipos de rocas presentes en ambos sitios. Para profundizar esta cuestión se deberán considerar aspectos vinculados a los tipos de fractura generados por talla y la acción de diversos agentes tafonómicos, objetivos que exceden a este trabajo. Por el momento consideramos que el alto índice de fracturas se debe mayormente a causas tecnológicas ya que las evidencias tafonómicas y zooarqueológicas registradas en ambos conjuntos avalan la buena preservación de los sitios (Salemme et al. 2014; Santiago et al. 2007).

\section{En relación a los restantes conjuntos del Holoceno medio}

Los contextos asignables a esta cronología en el norte de Tierra del Fuego son escasos y es muy dispar la información disponible dado que han sido estudiados bajo distintos proyectos/objetivos, contemplando diferentes variables.

La ausencia de puntas de proyectil y la baja representación de tecnología bifacial en los contextos de estratigrafía de LA2 y RCh1 podría vincular los conjuntos con otros 
contextos de similar cronología, como son los casos de los sitios Myren 2 (ca. 4000 años AP) y Monmouth 20 (ca. 5000 ARCP, Morello et al. 2009b).

En el sitio Myren 2 los materiales líticos recuperados suman un total de 36 piezas, en donde predominan los artefactos tallados por percusión. Entre los artefactos con formatización secundaria el grupo más representado es el de las raederas seguidas por las bolas. En cuanto a las etapas de manufactura llevadas a cabo en el sitio, la mayor representación de lascas internas es interpretada como indicador del desarrollo de instancias finales en la formatización de artefactos (Prieto et al. 2007). Los autores resaltan respecto a las bolas $(n=3)$ el parecido con algunas piezas de Marazzi 1, especialmente en materia prima y también en morfología y profundidad del surco.

En el sitio Monmouth 20 un porcentaje muy bajo de los artefactos líticos posee formatización secundaria. Las actividades de talla identificadas señalan un mayor énfasis en el desbaste de núcleos y en inferior proporción, tareas vinculadas a la formatización secundaria de artefactos. La talla bifacial, si bien con baja frecuencia, fue desarrollada en el sitio (Morello et al. 2009b). En el total de los materiales recuperados se observa un marcado predominio de desechos $(93,6 \%)$. Los artefactos con formatización secundaria están representados por un 2,8\% del total. La única pieza a la cual se atribuye el trabajo bifacial es una lasca.

Respecto al sitio Marazzi 1, con un volumen de material muy superior a los antes mencionados, podrían diferenciarse dos cuerpos principales de información: aquella procedente del re-estudio de la colección recuperada por la Misión Francesa (Morello 2000) y el material registrado en la nueva excavación de los testigos dejados en la excavación original (Morello et al. 1999), a lo cual se agrega el estudio más reciente de Huidobro (2010).

El material asignable al nivel medio, datado en 5570 ARCP, del primer conjunto se caracteriza por su variabilidad, ya que hay evidencias de todas las etapas productivas de manufactura $y$, entre ellos, hay un bifaz (Morello 2000). El conjunto se completa con pocos núcleos, pero relativamente abundantes percutores y numerosos desechos de talla. Esta última es la categoría más representada (78,9\% en su mayoría lascas), destacándose la ausencia de microlascas. En relación a la técnica bifacial, la autora resalta el predominio relativo de lascas de rebaje bifacial en niveles inferiores y su baja presencia entre los niveles medios (Morello 2000).

Luego de la apertura y re-excavación del sitio (Morello et al. 1999) se definen cuatro estratos. El estrato II, correspondiente al Holoceno medio, concentra la mayor cantidad de restos culturales. Allí se registraron una variedad de materiales líticos, con gran cantidad de desechos de talla, dos preformas bifaciales y varios artefactos con formatización secundaria (los más frecuentes son raederas y percutores; Morello et al. 1999). Se confirma que durante el Holoceno medio se realizaron en el sitio una serie de actividades que abarcan toda la secuencia operativa de manufactura lítica. Las técnicas identificadas son múltiples e incluyen la bifacialidad.

Huidobro (2010), analizó el material lítico obtenido en las excavaciones de 1968-69 ( $n=3153), 1998(n=233)$ y $2008(n=75)$ - este último proveniente de un sondeo del sitio Marazzi 1. Si bien la autora reafirma los estudios anteriores al observar que las actividades de talla bifacial son siempre minoritarias y se evidencia un descenso en su frecuencia desde ocupaciones más tempranas hacia el Holoceno medio (Laming Emperaire et al. 1972; Morello 2000), su estudio pone de manifiesto una relevancia mayor en la representatividad de la técnica bifacial para los niveles medios, produciéndose las etapas iniciales de confección de artefactos bifaciales, con el uso de percusión dura y blanda. En el sitio no se llevarían a cabo las etapas finales de formatización de los artefactos bifaciales, dada la baja proporción de desechos de retoque. Estas evidencias apuntan al transporte de los productos de talla bifacial fuera del sitio, al menos para los niveles medios (Huidobro 2010).

Cabe aquí resaltar consideraciones que nos alertan sobre la dificultad de efectuar una caracterización general para los conjuntos del Holoceno medio. Por un lado, Huidobro (2010) resalta un aspecto fundamental en su análisis del conjunto lítico procedente del sitio Marazzi 1: las formas base utilizadas poseen dimensiones muy superiores a los productos finales. Como consecuencia se produjeron múltiples instancias de reducción obteniendo lascas de las cuales se aprovecharon sus filos naturales o bien se formatizaron secundariamente.

Estos resultados alentaron el desarrollo de un estudio más detallado de los desechos de talla, especialmente las lascas en LA2 y RCh1, ya que esta categoría artefactual podría guardar pruebas del empleo de la técnica de talla bifacial y posterior traslado de los productos. De momento, tras el análisis del $55 \%$ de los desechos en ambos sitios no hay evidencia que apunte en esa dirección, ya que se observa una baja presencia tanto de artefactos como de desechos bifaciales. En este sentido los artefactos bifaciales de LA2 y RCh1 habrían sido manufacturados y descartados in situ.

Por otro lado, si se consideran los distintos registros del sitio LA2 se observan importantes diferencias. Por ejemplo, la presencia de bolas $y$, en particular, es sugerente la presencia de raederas bifaciales en superficie, próximas al sitio (Salemme et al. 2007; Santiago 2013). Al considerar que en RCh1 sólo se excavaron $3 \mathrm{~m}^{2}$ resulta fundamental adjudicar en primera instancia la ausencia de tecnología bifacial a cuestiones vinculadas con el muestreo. Esta observación abre una expectativa para proponer una vía 
hipotética que vincule estos contextos cronológicamente contemporáneos: existen claras similitudes en las materias primas explotadas, la presencia de bolas y la ausencia de cabezales líticos. La diferencia más marcada, relacionada al registro de reducción bifacial, podría estar enmascarada por la diferencia en el volumen excavado.

\section{Consideraciones finales}

El presente trabajo cumple con el objetivo de ofrecer nueva información tecnológica sobre dos contextos del Holoceno medio y resalta aspectos comunes para ambos sitios, tales como la presencia de todas las etapas de la cadena operativa, técnica "Levallois", bajos porcentajes de bifacialidad, preponderancia de retoque marginal y ultramarginal en los artefactos formatizados, altos porcentajes de artefactos fracturados y ausencia de puntas de proyectil.

Así mismo, hemos identificado diferencias respecto a: la ausencia de bolas en RCh1, la presencia de tamaños mayores de núcleos y desechos en LA2, una mayor presencia de desechos de toba silicificada en RCh1 así como un aprovechamiento más intensivo de los núcleos de esta materia prima. Por otra parte, en LA2 los artefactos con formatización secundaria no solo son más abundantes $(2,8 \%$ en LA 2 versus $0,9 \%$ en RCh1, Tabla 2) sino que además muestran una mayor variabilidad morfológica, que incluye artefactos con retalla perimetral, lascas con pocos retoques, filos largos retocados, simples o dobles y artefactos manufacturados por abrasión, picado y pulido.

El presente trabajo es un aporte en pos de avanzar en el conocimiento de los aspectos tecnomorfológicos de los conjuntos procedentes del norte fueguino. El objetivo central fue realizar una primera comparación con otros conjuntos en estratigrafía con la misma asignación cronológica para evaluar si las tendencias observadas en LA2 y RCh1 se asemejan a aquellas presentes en otros conjuntos del Holoceno medio.

Ushuaia, noviembre de 2013

\section{Agradecimientos}

Parte de este trabajo fue subvencionado en el marco del proyecto PIP CONICET 0422-10. Las Estancias María Behety y Los Flamencos, a través de sus administradores (Patricio Suárez e Ivon Roberts, respectivamente), facilitaron el acceso al lugar de trabajo; el personal de la Estación Astronómica Río Grande (EARG) y la empresa ROCH apoyaron logísticamente; Germán Pinto, Tomás Luppo, Belén Colasurdo, Melina Coll, Julieta Sartori, Alejandra Raies participaron de los trabajos de campo; los autores son los únicos responsables de las ideas aquí expresadas. Quisiéramos agradecer los comentarios acertados de los evaluadores que enriquecieron sensiblemente este manuscrito.

\section{Bibliografía}

Ahler, S. A. 1989. Mass analysis of flaking debris: studying the forest rather than the tree. En D. Henry y G. Odell (eds.) Alternative approaches to lithic analysis. Archaeological Papers of the American Anthropological Association 1: 85-118.

Andrefsky W. 1998. Lithics: Macroscopic Approach to Analysis. Cambridge University Press, Cambridge.

Aschero, C. 1975. Ensayo para una clasificación morfológica de artefactos líticos aplicada a estudios tipológicos comparativos. 116. Buenos Aires: Informe presentado al CONICET, MS.

Bellelli, C. y D. M. Kligman, 1996. Identificación de procesos de producción lítica a través del análisis de desechos de talla. II Jornadas de Arqueología de la Patagonia: 307-317.

Bellelli, C; A. G. Guráieb y J. A. García. 1985-1987. Propuesta para el análisis y procesamiento por computadora de desechos de talla lítica (DELCO - Desechos líticos computarizados). Arqueología Contemporánea 1 (II): 36-53.

Bonomo, M. 2004. Ocupaciones humanas en el litoral marítimo pampeano. Un enfoque arqueológico. Tesis Doctoral inédita. Facultad de Ciencias Naturales y Museo, Universidad Nacional de La Plata.

Borrazzo, K. B. 2012. Raw material availability, flaking quality, and hunter-gatherer technological decision making in northern Tierra del Fuego Island (southern South America). Journal of Archaeological Science 39: 2643-2654.

Cogliati, M. y M. Cuello. 2007. El clima de la Patagonia. Patagonia Total, Antártida e Islas Malvinas: 618-643. Barcel Bayres Ediciones.

Collado, L. 2007. La vegetación de Tierra del Fuego: de la estepa a la selva. Patagonia Total, Antártida e Islas Malvinas: 755-772. Barcel Baires. Buenos Aires.

Coronato, A. 2007. El paisaje de Tierra del Fuego. Patagonia Total, Antártida e Islas Malvinas: 601-617. Barcel Baires. Buenos Aires.

Doelman, T. 2002. Time to Quarry: The archaeology of stone procurement in northwestern New South Wales. Ph.D. Thesis. School of Archaeology, La Trobe University, Melbourne.

Favier Dubois C. y L. Borrero 2005. Playas de acreción: 
Cronología y procesos de formación del registro arqueológico en la costa central de la Bahía San Sebastián, Tierra del Fuego (Argentina). Magallania 33 (2): 83-98. Punta Arenas, Chile.

Guichón, R. 1994. "Antropología física de Tierra del Fuego: caracterización biológica de las poblaciones prehispánicas". Facultad de Filosofía y Letras. Universidad de Buenos Aires. Argentina. Tesis Doctoral,

Hiscock, P. 2002. Quantifying the size of artifact assemblages. Journal of Archaeological Science 29:251-258.

Huidobro, M. C. 2010. "Métodos de reducción bifacial del norte de Tierra del Fuego durante el Holoceno Medio y Tardío". Facultad de Ciencias Sociales, Departamento de Antropología, Carrera de Arqueología. Universidad de Chile, Chile. 217. Tesis de licenciatura.

Iturraspe, R. y A. Urciuolo 2007. Los recursos hídricos de Tierra del Fuego. Patagonia Total, Antártida e Islas Malvinas: 733-753. Barcel Bayres Ediciones.

Laming-Emperaire, A., D. Lavallee y R. Humbert. 1972. Le site de Marazzi en Terre de Feu, en Objets et Mondes, XII (2): 225-224.

McCulloch R. D. y F. Morello. 2009. Evidencia glacial y paleoecológica de ambientes tardiglaciales y del Holoceno temprano. Implicaciones para el poblamiento temprano de Tierra del Fuego. En: Salemme, M., F. Santiago, M. Alvarez, E. Piana, M. Vázquez y M.E. Mansur (eds.) Arqueología de la Patagonia. Una mirada desde el último confín, 1: 119-133. Editorial Utopías. Ushuaia.

McCulloch R. D., C. J. Fogwill, D. E. Sugden, M. J. Bentley y P. W. Kubik. 2005. Chronology of the Last Glaciation in central Strait of Magellan and Bahía Inútil. Geografiska Annaler 87A: 289-312.

Morello, F. 2000. 30 años después, una primera aproximación a la colección Marazzi (Museo Regional, Punta Arenas). Desde el País de los Gigantes. Perspectivas arqueológicas en Patagonia II: 481-497. Universidad Nacional de la Patagonia Austral. Río Gallegos.

Morello, F. 2005. Tecnología y métodos para el desbaste de lascas en el norte de Tierra Del Fuego: los núcleos del sitio cabo San Vicente. Magallania 33(2): 29-56.

Morello, F., L. Contreras y M. San Román. 1999. La localidad Marazzi y el sitio arqueológico Marazzi I, una reevaluación. Anales del Instituto de la Patagonia, Serie Ciencias Humanas 27: 183-197.

Morello, F., L. A. Borrero, J. Torres, M. Massone, M. Arroyo, R. McCulloch, E. Calás, M. J. Lucero, I. Martínez y G. Bahamonde. 2009a. Evaluando el registro arqueológico de Tierra del Fuego durante el Holoceno temprano y medio. En: Salemme M., F. Santiago, M. Álvarez, E. Piana, M. Vázquez y E. Mansur (eds), Arqueología de la Patagonia. Una mirada desde el último confín, II: 10751091. Editorial Utopías. Ushuaia.

Morello F., M. Arroyo, L. Borrero, J. Torres, M. Massone, P. Cárdenas y G. Bahamonde, 2009b. Nuevas evidencias de cazadores recolectores terrestres del Holoceno Medio y Tardío en Tierra del Fuego: El sitio Cabo Monmouth 20. Magallania 37 (2): 193-205.

Morello, F., L. Borrero, M. Massone, C. Stern, A. GarcíaHerbst, R. Mcculloch, M. Arroyo-Kalin, E. Calás, J. Torres, A. Prieto, I.Martinez, G. Bahamonde y P. Cárdenas, 2012. Hunter-gatherers, biogeographic barriers and the development of human settlement in Tierra del Fuego. Antiquity 86 (331): 71-87.

Nami, H. G.1992. Noticia sobre la existencia de técnica "Levallois" en Península Mitre, extremo sudoriental de Tierra del Fuego. Anales del Instituto de la Patagonia 21: $73-80$.

Oría, J. 2012. "Patrones de movilidad pre-europeos en el norte de Tierra del Fuego: una aproximación geoarqueológica". Facultad de Ciencias Naturales y Museo, Universidad Nacional de La Plata. Argentina. 545. Tesis Doctoral.

Orquera, L. y E. Piana. 1986. Normas para la descripción de objetos arqueológicos de piedra tallada. CADIC, Contribución Científica (Publicación especial) Nº 1: 1-198, Ushuaia.

Pal, N. 2012. "Tendencias temporales en las estrategias de explotación y uso de los materiales líticos de la cuenca superior del arroyo Tapalqué (Partidos de Benito Juárez y Olavarría): Una perspectiva desde el Análisis Funcional". Facultad de Ciencias Sociales, Universidad Nacional del Centro de la provincia de Buenos Aires. Olavarría. Argentina. 476. Tesis Doctoral inédita.

Paulides, L. S. 2006. El aprovisionamiento y la explotación de materias primas líticas en el sistema serrano de Tandilia. El complejo de Canteras de Arroyo Diamante. Serie Tesis de Licenciatura, Departamento de Ciencias Antropológicas, Facultad de Filosofía y Letras - U.B.A, CD-Rom n 1, 1a Ed., Buenos Aires.

Prieto, A., E. Calás, F. Morello y J. Torres. 2007. El sitio arqueológico Myrén 2, Tierra del Fuego, Chile. Magallania 35 (2): 89-103.

Rabassa, J., A. Coronato y J. F. Ponce. 2009. La depresión de Bahía Inútil - Bahía San Sebastián (Tierra del Fuego, Argentina - Chile): una conexión marina inexistente durante el Pleistoceno tardío-Holoceno. En: Salemme, 
M., F. Santiago, M. Alvarez, E. Piana, M. Vázquez y M.E. Mansur (eds.) Arqueología de la Patagonia. Una mirada desde el último confín, 1: 101-108. Editorial Utopías. Ushuaia.

Salemme, M. C. y G. Bujalesky. 2000. Condiciones para el asentamiento humano litoral entre Cabo San Sebastián y Cabo Peñas (Tierra del Fuego) durante el Holoceno medio. En Desde el país de los gigantes. Perspectivas arqueológicas en Patagonia, II: 519-531. Universidad Nacional de la Patagonia Austral, Rio Gallegos.

Salemme, M. C., G. G. Bujalesky y F. C. Santiago. 2007a. La Arcillosa 2: La ocupación humana durante el Holoceno Medio en el Río Chico, Tierra del Fuego, Argentina. En: Morello, F. M. Martinic, A. Prieto y G. Bahamonde (eds.), Arqueología de Fuego-Patagonia. Levantando piedras, desenterrando huesos... y develando arcanos: 723-739. Punta Arenas, Chile.

Salemme, M. C., F. Santiago, J. Suby y R. Guichón. 2007b. Arqueología funeraria en el norte de Tierra del Fuego. XVI Congreso Nacional de Arqueología Argentina, Simposio El mundo funerario y la sociedad, II: 71-77. Jujuy.

Salemme, M., F. Santiago y J. Oría. 2014. La Arcillosa 2: nuevos datos zooarqueológicos de un conchero del Holoceno medio. Revista Chilena de Antropología. En prensa.

Santiago, F. 2009. Dos sitios del norte de Tierra del Fuego "sondeados" con GPR: Río Chico 1 y La Arcillosa 2. En: Bourlot, T., D Bozzuto, C. Crespo, A.C. Hecht y N.
Kuperszmit (eds.), Entre pasados y presentes II: 171-183. Fundación Félix de Azara.

Santiago, F. 2013. La ocupación humana en el norte de Tierra del Fuego durante el Holoceno medio y tardío. Su vinculación con el paisaje. Editora Cultural Tierra del Fuego. $460 \mathrm{p}$.

Santiago, F., J. Oría J. y M. Salemme. 2007. Nuevo contexto arqueológico del Holoceno medio. Río Chico 1. Tierra del Fuego, Argentina. XVI Congreso Nacional de Arqueología Argentina. Tras las Huellas de la Materialidad, III: 439-445. San Salvador de Jujuy.

Santiago, F., M. Salemme, J. Suby, R. Guichón. 2011. Restos humanos en el norte de Tierra del Fuego. Aspectos contextuales, dietarios y paleopatológicos. Intersecciones en Antropología 12: 147-162. Olavarría.

Shott, M. J. 1994. Size and form in the analysis of flake debris: review and recent approaches. Journal of Archaeological Method and Theory 1(1): 69-110.

Valverde, F., 2003. Análisis de los desechos líticos de la ocupación inicial del sitio cueva Tixi (Provincia de Buenos Aires): cadena operativa de producción y técnicas de talla tempranas. Relaciones de la Sociedad Argentina de Antropología 28: 185-202.

Vallin, L. 1992. De l'intérêt d'une recherche sur les formes predeterminées de débitage dans l'extrême-sud américain, pp. 10, Lille. MS. 